\title{
Climate Change and International Civil Aviation Negotiations
}

\section{Veronica Korber Gonçalves*}

\begin{abstract}
The International Civil Aviation Organization (ICAO) has discussed ways of regulating greenhouse gas (GHG) emissions by civil aircraft for almost 20 years. Over the past four years, a consensus has developed about a market-based mechanism in the form of a carbon offset system. This article describes the route to the agreement reached by ICAO's $39^{\text {th }}$ Assembly, in order to contextualise the results and point out some of its limitations. It points to two main factors that contributed to the consensus: the role of the European Union, which sought to lead the negotiations, and the choice of a flexible and ultimately weak mechanism that received support from the international airlines.
\end{abstract}

Keywords: Climate Change; International Civil Aviation; ICAO; Offset System; Climate Regime.

\section{Introduction}

The aviation sector is one of the main emitters of greenhouse gases (GHG). Civil aviation emissions, including domestic and international flights, account for about $2.5 \%$ of global GHG emissions. If the aviation sector were a country, it would be the seventh biggest polluter in the world. Moreover, emissions from aviation are growing exponentially; according to the International Civil Aviation Organization (ICAO), if current trends continue, emission levels in 2036 will be between 155\% and 300\% higher than in 2006 (ICAO 2013a).

After years of negotiations, ICAO finally addressed this issue at its 39th General Assembly held in Montreal, Canada, from 27 September to 7 October 2016 (Campos 2016; Vaishnav 2016), in the form of an agreement setting out the basis of a global market-based mechanism for offsetting $\mathrm{CO}_{2}$ emissions from international flights, and a 'roadmap for the sustainable future of international aviation' (ICAO 2016a).

The General Assembly is ICAO's sovereign body, comprising representatives of 191 member states. International organisations are also invited to attend. Almost 20 years had elapsed since it was decided that ICAO would be the appropriate forum for discussing and deciding on actions involving international civil aviation. Since then, it had produced various studies, and promoted debates, but failed to reach a binding agreement.

Federal University of Rio Grande do Sul (UFRGS), Porto Alegre-RS, Brazil; veronica.goncalves@ufrgs.br 
This article aims to trace the route to the agreement, formalised in Resolution A393, entitled 'Consolidated statement of continuing ICAO policies and practices related to environmental protection - Global Market-based Measure (MBM)'. My main goal is to contextualise the resolution, and point out some of its limits. I will also set out general guidelines to the structure to be created at ICAO to deal with aviation emissions.

In doing so, I will reflect upon the process of constructing an international agreement based on the analysis of the state and non-state actors relevant to the formation of consensus or disputes around the given issue. The context of negotiations allows one to develop an understanding of its results in terms of 'advances' and 'limits', derived from a set of relations established among actors in a specific forum and in a determined period, rather than from an unrelated set of normative assumptions.

In what follows, I describe the negotiations about GHG emissions at ICAO, emphasising the role of the European Union (EU), which played an important role in promoting the negotiations, as well as the role of the airline companies, which collaborated to postpone negotiations. Next, I examine the agreed market-based mechanism for regulating aviation GHG emissions, pointing to some of its limits.

\section{From the climate regime to the international civil aviation regime}

Although this article largely addresses the response of the international civil aviation regime to climate change, I will briefly deal with the issue of how this intersection with the climate regime occurred, when it was decided that ICAO, and not the UN Framework Convention on Climate Change (UNFCCC), was the competent forum for dealing with GHG emissions by civil aircraft. In what follows, I outline the relevant legal and institutional frameworks of the climate regime, and then present the structure of ICAO, pointing out some substantial differences between these two negotiating forums.

\section{Climate regime}

Debates about climate change started in the second half of the previous century; however, they were initially restricted to its scientific causes and effects, and were mainly academic. This changed in 1979 when the First World Climate Conference adopted a declaration urging governments to take steps to prevent climate change of anthropic origin that could compromise the well-being of mankind (Zillman 2009). The conference also established the World Climate Research Programme.

In 1988, the UN Environment Programme (UNEP) and World Meteorological Organization (WMO) established the Intergovernmental Panel on Climate Change (IPCC), which produces reports about climate change and its impacts, based on available scientific information. The IPCC does not produce new research, or monitor data related to climate change; instead, it gathers existing scientific, technical and socio-economic data relevant to an understanding of climate change, and presents this in ways suited to informing international debate and action. The IPCC is one of the most important actors in the climate regime, basing its authority on its scientific expertise. Its reports give scientific legitimacy 
to demands for new policy regimes, including those related to international civil aviation (IPCC 1999, 2013, 2014; ICAO 2016a).

In 1992, the UN Conference on Environment and Development (Earth Summit-92) held in Rio de Janeiro, Brazil, adopted the UN Framework Convention on Climate Change (UNFCCC), which came into force on 21 March 1994. Its goals include the 'stabilization of greenhouse gas concentrations at a level that would prevent dangerous anthropogenic (human-induced) interference with the climate system' (UNFCCC 2017). The Convention provides for a Conference of Parties (COP) as its supreme decision-making body, comprising representatives of all states that are signatories to the Treaty. At its periodic meetings, the Parties review implementation of the convention, exchange data and information about policies adopted to achieve the objectives pursued, and make decisions related to the implementation of the convention. Up to December 2016, the COP had met 21 times.

In 1997, UNFCCC COP-3, held in Japan, signed the Kyoto Protocol which, for the first time, committed the parties named in Annex 1 of the Convention to binding emission reduction targets. ${ }^{1}$ Article 3 of the Protocol requires Annex I Parties to ensure that their GHG emissions (not controlled by the Montreal Protocol ${ }^{2}$ ) do not exceed their commitments in Annex B, aiming to reduce it by at least 5\% below 1990 levels (UNFCCC 2016). The Protocol established a first commitment period of 2008 to 2012. Taking into consideration the principle of common but differentiated responsibilities, ${ }^{3}$ the common obligation of all Parties (Annex I and non-Annex I) consists in formulating, to the extent that they are able, national programmes to improve GHG emission factors, and develop national emission inventories based on specific sectors of the economy; formulating, implementing, publishing and updating national programmes for mitigating climate change; and collaborating on international research about climate change. The Protocol entered into force on 16 February 2005.

The Protocol stated that emissions by domestic civil aviation should be included in the inventories held by Annex I Parties. It did not, however, include emissions by international civil aviation (which includes the transport of cargo and people in short and longdistance international flights, and at regular or low cost), and referred the issue to another forum, namely ICAO. ${ }^{4}$

Three flexibilisation mechanisms have been established to help parties achieve their goals, namely Joint Implementation (JI), the Clean Development Mechanism (CDM), and Emissions Trading. These mechanisms are the 'starting point' for establishing the carbon market. The CDM is structured as an offset system, and will serve as a model for the system created at ICAO, which I will deal with later.

In December 2015, UNFCCC COP-21, held in France, signed the Paris Agreement. Unlike the Kyoto Protocol, which establishes top-down legally binding commitments, the Paris Agreement introduces a bottom-up strategy of voluntary reduction targets called Intended Nationally Determined Contributions (INDCs).

The agreement establishes a new market mechanism, the sustainable development mechanism, to be supervised by a body designated by the COP. Among other things, Article 6 states that the mechanism should collaborate to promote the mitigation of GHG 
emissions, and deliver an overall mitigation of global emissions (Art 6.4). The agreement was considered a diplomatic victory, given that, after more than 20 years, it finally formalised a multilateral consensus about climate change, also encompassing the largest emitters. However, it does not mention emissions from international civil aviation, which further strengthens ICAO's status as the forum of choice for dealing with international aviation emissions.

\section{The international civil aviation regime}

ICAO was established in 1944 by the Convention on International Civil Aviation, known as the Chicago Convention (ICAO [1944] 2017). It is a specialised UN agency with its own structure and funding system, and forms part of the UN Economic and Social Council (ECOSOC). Headquartered in Montreal, Canada, it currently has 191 member states. Its main purpose is to serve as a global forum for regulating civil aviation. At ICAO, states negotiate policies, rules and standards, and produce studies and analyses. ICAO is governed by two bodies: the Assembly, comprising representatives of all member states, which meets at least once every three years; and a permanent body, the Council, comprising representatives of 36 member states elected for three-year periods. The Council convenes the Assembly, appoints the Secretary General, produces reports, and clarifies issues related to the Chicago Convention. Under the Chicago Convention, the Council reports infractions of or non-compliance with rules and resolutions to ICAO's Triennial Assembly. ${ }^{5}$ As its name suggests, the Assembly is held at least once every three years, usually in September, in the city of Montreal.

In order to help member states implement the Chicago Convention, ICAO has established five strategic objectives, namely: 1) Safety; 2) Air Navigation Capacity and Efficiency; 3) Aviation Security and Facilitation; 4) The Economic Development of Air Transport; and 5) Environmental Protection.

As regards the last-named objective, the two main problems are aircraft noise (for which ICAO has already defined standards), and GHG emissions. Over the years, the debate about emissions has centred on setting reduction targets, taking into account the data and reports produced by ICAO's Committee on Aviation and Environmental Protection (ICAO-CAEP). The committee is a technical body created in 1983 specifically to formulate and recommend policies about aircraft noise pollution and GHG emissions.

The ICAO Assembly has repeatedly stated its intention to continue exercising leadership over all issues involving international aviation, including GHG emissions (as in paragraph 2a of Resolution A39 -2). As a result, CAEP has been working on proposed standards for modernised procedures, technological innovation, and alternative fuels. However, between 1997 and 2008, very little progress was made towards building the minimum consensus needed to reach an agreement on emission reductions.

A major problem was the intensive efforts by commercial airlines to slow down the negotiations. They are represented in ICAO by the Air Transport Action Group (ATAG) and the International Air Transport Association (IATA), an association created in 1945 that encompasses more than 250 companies (more than $80 \%$ of the sector) today. 
Other important reasons for the slow negotiations were the unassertive position of USA, which contributed significantly to the discussions and the production of technical material, but until 2013 did not give any political signals about how it believed the debate should be conducted; and the refusal, until 2014, of developing countries to accept reduction targets. Prominent among them were China and Brazil, which recently adopted a more participatory approach, and India, which maintains a rigid interpretation of the categorisation of developed and developing countries.

When the debate about GHG emissions by the international aviation sector was moved from the climate field to the international aviation field, this represented a choice to deal with these emissions in a specific forum (ICAO), via a set of actors (states, airline organisations and companies) negotiating in a specific way, and based on specific norms and principles. For example, the implicit and explicit principles that guide and influence ICAO are derived from the preservation of the aviation sector and a guarantee of its expansion, which forms the basis for this negotiating forum, and not combating climate change, which would be the working premise of the UNFCCC. Therefore, the debate about emissions reductions or compensation measures can be understood as a concession by the sector rather than a sensitisation to its contribution to climate change.

ICAO is a highly traditional organisation, with a history of decades of formal and informal procedures. Its working groups and lobbies are well organised and consolidated, and aircraft manufacturers and operators are very successful in influencing the governments of their countries of origin. Therefore, the field of civil aviation is permeated by a strong sense of 'nationalism' and national sovereignty, encompassing the roles of state and non-state actors alike. As two analysts have noted, 'Air transportation is a highly regulated and monitored industry. Institutional settings and regulatory frameworks impact significantly on airlines' operations, and thus on their technical and environmental efficiency' (Arjomandi and Seufert 2014: 6).

The climate field could have major cost implications for the air transport industry, which is why they have organised to repel it. The preamble to Resolution A38-18 of 2013 states that the Assembly:

urges that ICAO and its Member States express a clear concern, through the UNFCCC process, on the use of international aviation as a potential source for the mobilization of revenue for climate finance to the other sectors, in order to ensure that international aviation would not be targeted as a source of such revenue in a disproportionate manner (ICAO 2013b: I-73).

In other words, the Assembly expresses its concern that the international civil aviation sector may be strongly associated with policies for coping with climate change. In October 2015, the president of ICAO, Olumuyiwa Benard Aliu, stated at the Global Sustainable Aviation Summit in Geneva that 'both ICAO and industry have been strongly united in our position on any proposed use of international aviation as a potential source for the mobilisation of general revenues to finance climate programmes in other sectors' (Greenair 2015). This stance reflects ICAO's intention to remove the debate about aviation 
emissions from the climate field ${ }^{6}$ (effectively the UNFCCC), and confirming its status as the relevant forum for dealing with this issue, while undertaking to debate climate issues and to make certain concessions.

\section{Progress on negotiations}

Given that negotiations at ICAO were not progressing, the EU considered including the aviation sector in its EU Emissions Trading System (EU ETS), ${ }^{7}$ which utilises a market-based mechanism (MBM), the cap and trade, ${ }^{8}$ to reduce carbon emissions in several sectors. At the ICAO Assembly in 2004, the EU succeeded in pushing through a resolution that paved the way for its proposed approach, namely the adoption of voluntary emissions trading schemes by states and international organisations. However, this started a debate about the need for mutual agreement among states about measures that would affect third parties - like an MBM that would encompass international aviation (Elsworth and MacDonald 2013). This means that, from 2004 to 2012, the debate was about the EU's intention to act unilaterally in the face of ICAO's inaction, with the other state and on-state actors challenging the legitimacy and legality of its proposed strategy.

Since then, IATA has consistently opposed any form of regulation that would not be global in scope (see Influence Map, IATA 2015), which means that it explicitly rejects the inclusion of international aviation in the EU Emissions Trading System (ETS).

In 2008, ICAO created a Group on International Aviation and Climate Change, tasked with developing a Plan of Action. In October 2009, the High Level Meeting on International Aviation and Climate Change adopted the Programme of Action on International Aviation and Climate Change. The PoA sets out emissions reduction targets to be reached via increases in energy efficiency, defines the need to develop methods for measuring the impacts of these actions, and provides a general outline for an MBM. MBMs are meant to achieve environmental goals at a lesser cost and in more flexible ways than traditional regulatory measures, such as command and control. Examples of carbon MBMs include carbon tax, the ETS, and offset systems.

In 2009, the EU approved the inclusion of the aviation sector in its ETS. A major reason was the fact that the sector is a major source of GHG emissions. In other words, given the lack of progress in multilateral negotiations, the EU adopted a unilateral measure with implications for third parties, as it stated that any aircraft landing on or taking off from EU soil should participate in the EU ETS.

This EU Aviation Directive provoked a strong international reaction, with both political and legal issues being raised. Almost all non-EU states participating in ICAO expressed their opposition to the fact that the directive covered international flights from non-EU countries. They argued that the measure was an unacceptable form of extraterritorial jurisdiction which violated their sovereignty, and that solutions to international aviation emissions should be built jointly in ICAO and not unilaterally.

While the EU declared that its directive was aimed at accelerating the ICAO negotiations, international reaction forced it to step back from its original goals and adopt an amended and far less ambitious directive, known as the Stop the Clock Decision (Gon- 
çalves 2016). It stated that, until September 2016, the directive would apply to domestic and international flights within the area of the European Economic Area (EEA Member States and Overseas Territories of the EEA), regardless of the country of origin of the aircraft. This excluded international civil aviation from the EU ETS.

Despite the fact that the EU had to modify its domestic policy, progress in the ICAO negotiations remained closely linked to negotiations with the EU about suspending its original directive. Therefore, in the negotiations up to 2012, the EU was a 'pusher' - i.e., the main driver for the regulation of GHG emissions by the international aviation sector. The US and developing countries can be characterised as 'laggards' (Dee 2011) - i.e., actors that worked for non-approval - together with the international airlines, which, although they are not formal ICAO members, have very efficient lobbies.

From 2012, negotiations about an economic instrument for offsetting a portion of aviation emissions intensified. Faced with various options for regulating and controlling emissions by the sector, including the establishment of global targets for issuing and forecasting noncompliance penalties (command and control rules), or state commitments to adopt domestic regulations, ICAO members opted for an economic instrument, similar to the choice made in the Kyoto Protocol.

Following the approval of the Aviation Directive, the debate about an MBM for the aviation sector intensified. In June 2012, the ICAO Council released an assessment of market-based measures (ICAO 2013a), which examined three possible models, namely a global cap and trade system; an emissions compensation system working through verified emission reductions in other sectors (global mandatory offsetting); and global mandatory offsetting combined with a revenue generation mechanism. A High-level Group comprising representatives of 17 countries (including the largest emitters) debated MBMs from November 2013 onwards.

When the MBMs were tabled at the 38th Assembly - mainly because of the negotiations with the EU - member states adopted a resolution (ICAO 2013b) hailed as 'historic'.

The resolution stated that a global MBM for reducing GHG emissions would be developed until 2016, and enter into force in 2020, as part of a set of measures that would include the development of more sustainable technologies and operations as well as alternative fuels. The preamble of the resolution refers to 'the importance of avoiding a multiplicity of approaches for the design and implementation of MBM framework and MBM schemes', which is a clear reference to the EU ETS.

A coalition of developing countries, comprising, China, India and Russia, succeeded in their efforts to include the principle that any future MBM would take into account the principles of common but differentiated responsibilities (a principle of the UNFCCC), non-discrimination, and fair and equal opportunities. This meant that developing states succeeded in winning recognition of the differentiation of responsibilities among states: essentially, this means that those countries which have exploited aviation for longer periods, and done so more intensively, must assume greater responsibility for dealing with the problem. Moreover, developing countries made sure the norm stated that when states create domestic or regional MBMs (such as the EU ETS), they should engage in 'construc- 
tive bilateral and/or multilateral consultations and negotiations with other States to reach an agreement' (ICAO 2013b).

The EU tried to insert a clause allowing states to create and maintain domestic or regional MBMs, such as the EU ETS, but this proposal was defeated by 97 votes to 39, with nine abstentions. The EU then submitted reservations to certain aspects of the resolution, including the principle of common but differentiated responsibilities (European Commission 2014), on the grounds that it could absolve developing countries from taking any action, despite the fact that they were responsible for a significant share of emissions. Ultimately, 61 countries submitted reservations or objections to Resolution A38-18 - a symptom of its weakness.

According to the NGO Sandbag Report, the ICAO agreement would not have been reached if it had not been for the EU ETS and the political storm that followed it (Elsworth and MacDonald 2013: 32). In this sense, the agreement should be seen as a victory, considering the huge political challenges involved, and it has to be recognised that the EU played a central role. This assessment is shared by various NGOs active in the sector: without the EU 'push', they say, no agreement on an MBM would have been reached. In short, the EU succeeded in its drive to introduce curbs on civil aviation emissions. However, its ambitions have been revised downwards, since it could not introduce its original goals, or even maintain its domestic policy.

As regards the airlines and their roles in the agreement, they have an institutional interest in restricting comments on measures for reducing the environmental impact of their activities to their annual reports and other print and electronic publications (often in sections on 'the environment'). Regarding carbon emissions, they advocate improving energy efficiency, and reducing emissions.

In 2008, ATAG stated the sector's main goals as follows, as reaffirmed at ICAO in 2012: a) Improving fleet fuel efficiency by $1.5 \%$ per year through until 2020; b) Stabilizing net emissions from 2020 through carbon-neutral growth, subject to concerted industry and government initiatives; and c) Reducing net aviation carbon emissions by $50 \%$ by 2050, relative to 2005 levels (ATAG 2013).

The airlines favour a market mechanism that is not too costly, which is why they support a compensation mechanism without rigid controls over the origins of the carbon reduction, and as long as it does not prevent the expansions of air routes. ATAG advocates a comprehensive agreement to avoid unilateral measures, stating: 'The safe, orderly and efficient functioning of today's air transport system relies on a high degree of uniformity in regulations, standards and procedures. The use of unilateral measures undermines this foundation' (ATAG 2013). So, in 2013, ATAG defended a market mechanism as long as it was global, and took into account different types of operation.

\section{The agreement to control international emissions from aviation}

I have outlined the negotiations that culminated in the first international agreement on GHG emissions from the international civil aviation sector at the $39^{\text {th }}$ ICAO Assembly in late 2016. I will now highlight some of its contents. 
Resolution 39-3 is the first comprehensive agreement on a MBM covering a specific industrial sector. It comes after more than two decades of negotiations, and results from the reconciliation of interests of various actors within ICAO. The initiative was led by the EU, the USA and China. Reservations about aspects of the final resolution submitted by Argentina, Russia, India and Venezuela provide evidence of its limits.

The resolution presents a global MBM as a complementary measure for achieving environmental and climate protection objectives without an inappropriate economic impact on the aviation industry. The preamble mentions the principle of common but differentiated responsibilities, taking into account different national circumstances.

This principle has also been central to climate negotiations, but has not been interpreted in the same way as in the climate regime. This explains the statement in the preamble that the resolution does not create a precedent for future negotiations under the UNFCCC and the Paris Agreement, as well as other climate regime agreements. It is, therefore, an arrangement of differentiation among countries that is valid only in the forum of international aviation, and does not set a precedent for developing countries in the climate regime.

The MBM is structured into a Carbon Offset and Reduction Scheme for International Aviation (CORSIA). It will comprise a pilot phase from 2021 until 2023; a voluntary first phase from 2024 to 2026; and a mandatory phase (with exceptions) from 2027 to 2035. The objective of the agreement is to limit the sector's GHG emissions to 2020 levels (base year). After that, airlines from participating countries will need to reduce or offset their exceeded emissions. Therefore, the regulation refers to surplus issued after 2021 on the basis of 2020 emissions. By October 2016, 66 states, representing more than $86.5 \%$ of aviation activity, had expressed their intention to participate voluntarily in the first phase, from 2024 until 2026 (ICAO 2016b).

Aircraft responsible for minimum levels of operation (emitting less than 10000 tons of $\mathrm{CO}_{2}$ a year); small aircraft (weighing less than $5700 \mathrm{~kg}$ ); and those used for humanitarian, medical, or firefighting activities are all excluded from the second phase. In addition, flights to and from less developed countries, small island developing countries, and landlocked developing countries are not required to participate in the system. Also, the resolution covers routes that connect countries participating in the scheme. If a flight leaves or lands in a country not covered by the scheme, it will not be counted, even if the destination or origin is a participating country (ICAO 2016a).

Despite efforts made during the negotiations, no link was established between ICAO's objectives and those of the Paris Agreement aimed at limiting the average global temperature increase by $2^{\circ}$ Celsius, with the prospect of maintaining an $1.5^{\circ}$ Celsius increase.

\section{The GMBM for international civil aviation}

The global MBM refers to a market mechanism that establishes the criteria for trading carbon credits, in order to meet the stated targets (in this case, maintaining GHG emissions by the aviation industry at 2020 levels). Emission units used in the GMBM are the result 
of carbon offset projects. In short, the offset model allows countries to offset emissions by their aviation industries against verified emission reductions in other sectors.

They may do so by buying or redeeming emission units from different sources of reductions, via mechanisms such as the Clean Development Mechanism (CDM), established under the Kyoto Protocol, its successor, the Sustainable Development Mechanism (SDM), programmes similar to Reducing Emissions from Deforestation and Forest Degradation Plus (REDD+), created under UNFCCC, as well as local projects, as long as they are audited (ICAO 2017b).

The carbon market involves the buying and selling of emission allowances and reduction credits valid under CORSIA. This means that airlines are not directly involved in emission reduction projects, but have to buy credits to compensate for their emissions.

From 2015 to 2016, negotiators focused on establishing quality criteria for valid credits, through Measurement, Reporting and Verification (MRV), as well as clear mechanisms for avoiding double counting. At the end of the $39^{\text {th }}$ Assembly, these points were not agreed, which raises doubts about the quality and environmental integrity of eligible credits as well as the mechanisms for monitoring compliance with the obligations.

The idea of compensating for carbon emissions by airline companies is not new. Many airlines already offer their consumers voluntary compensation mechanisms in the form of investments in emissions reduction projects. CORSIA has transformed this voluntary individual compensation mechanism into a company obligation to compensate for the entire flight. Numerous companies already have voluntary compensation systems, like Fly Carbon Neutral by Virgin Australia, Qantas and Jetstar, all certified by the Australian government (Australian Government 2016). Besides this, there are other voluntary compensation programmes with different methods for calculating carbon emissions, and different criteria for verifying implementation.

IATA itself has created a voluntary compensation programme, the IATA Airline Offset Programme. Participants include British Airways (UK), Cathay Pacific and Dragonair (China), Etihad Airways (UAE), Kenya Airways (Kenya), and Lufthansa (Germany) (IATA 2016). And in Brazil, LATAM Airlines have undertaken a voluntary partial carbon offset programme (Latam Airlines Group 2015: 34).

Before the ICAO Assembly, 80 NGOs (including the largest environmental NGOs such as Greenpeace and Friends of the Earth International) signed a declaration opposing the proposed compensation scheme (FERN Foundation 2016), claiming that offsetting would not reduce emissions as it would allow the aviation sector to compensate for its emissions only, and further expand its operations. The flexibility of the offset system helps to explain the airlines' support for this system in the ICAO negotiations, considering that it requires very little direct action and allows the dilution of environmental responsibility of the projects, as discussed below.

\section{Limits of the compensation of carbon emission model}

ICAO's chosen model is fragile from an environmental and climatic point of view, especially if we consider the contribution of the aviation sector to climate change. Under the 
offset model, airlines only have to prove - and only from 2027 onwards -- that they are compensating for increases in emissions since 2020, via the purchase of units from capture projects or emission reduction schemes.

This significantly reduces the positive environmental impact of the ICAO agreement, insofar as it symbolically disconnects the problem (emissions) from the response (reduction). That is, instead of addressing the problem and the solution within the field of aviation, it symbolically 'dilutes' the problem with by displacing the response to other sectors, where the costs of action are lower, thus avoiding the decarbonisation of the aviation sector itself. To illustrate: the system makes two situations equivalent - in the first, one flight emits $\mathrm{x}$ tons of carbon. In the second, two flights emit $2 \mathrm{x}$ tons of carbon, but $1 \mathrm{x}$ is compensated for by planting trees. That is, traditional emissions are equated with increased traditional emissions allied to emission reduction projects. This can result in a 'zero account' if the only focus is carbon emissions (a 'carbon-centric' approach), ignoring other social and environmental impacts. However, there is no real gain for airlines, which could claim to be part of the solution without actually reducing their emissions.

This territorial decoupling promoted by the emissions compensation model can be explained with the notion of a 'policy of the scales' (Gupta 2008). According to this author, the global scale approach allows the environmental externalities of a given problem to be acknowledged. The global scale can give greater visibility to a theme, and ensure the involvement of a greater number of actors and institutions, which can be positive in a situation where no actor wants to or can afford all the costs of dealing with a major environmental problem (such as climate change). Besides this, an actor may seek to establish a problem on a global scale in order to promote domestic interests, avoiding expensive individual actions and involving third parties in its actions (e.g., establishing a certain technology / standard); influencing the resources of another actor (e.g., the regulation of biodiversity), or postponing action, since at the international level the decision-making process tends to be slower (Gupta 2008). Reasons for trying to modify the scale to a local scale including better knowledge and administration of the social context, greater control of activities, as well as less openness to external interference (Gupta 2008).

In short, shifting the scale can strengthen the legitimacy of a given approach, both to define the problem and to establish the policy instruments needed to address it. By shifting the scale closer to global, the resources and the number of people involved increase, but so does the possibility of divergence and conflicts of interest. By moving closer to the local scale, the problem becomes more manageable, but this can lead to the internalisation of extraterritorial impacts.

When we analyse the offset model from the politics of scale perspective, it becomes clear that shifting the problem (global aviation emissions) and the response (compensation projects at the local level) to different scales has the effect of decoupling the cause of the problem and the solution. Moreover, it helps to break the legal connection (legal responsibility) between the actor causing the problem, and the possible side effects of the solution. Finally, it is worth pointing out that CORSIA tends to foster the creation of projects in countries in the Global South which are already recipients of the CDM and REDD+ projects, which has led to negative impacts on surrounding populations and lo- 
cal environments (as observed by Gonçalves 2007; Böhm and Dabhi 2009; Dooney 2009; Gilbertson and Reyes 2009).

After almost 20 years of negotiations at ICAO, Resolution 39-3 has established a system for addressing GHG emissions by the international civil aviation sector. If we take a closer look at CORSIA, however, it becomes clear that this is a response significantly below the challenges it is proposing to face, due to its deadlines, the type of mechanism established (offsetting), and even the lack of definition of measurement and verification. It is a palatable response for states and airline companies, which are reluctant to curb growth in demand for international aviation services, which are still serving less than 5\% of the world`s population. In this sense, although ' $\mathrm{t}]$ he climate impacts from air travel are caused by only $2 \%$ of the world population that actively takes part in air travel' (Carbon Market Watch 2013: 1), the responsibility for dealing with its cost and effects is imputed to all people, and the delay in taking action (justified on the basis of fear of harm to the sector) also affect all people.

\section{Conclusion}

After years of negotiations, states finally agreed at ICAO to address GHG emissions by international civil aviation. This is an important step towards recognising the problem of climate change, and the sector's contribution to this problem. However, CORSIA falls significantly short of the challenges it sets out to address. It does not promote the direct reduction of GHG emissions, but only compensation. In other words, the aviation sector can expand its activities and emissions as long as it invests in offset projects. Due to the extended deadlines, the type of mechanism (offsetting), and even the lack of definitions of measurement, report and verification, it is possible to argue that this does not accord with the principles and objectives of the climate regime.

Put differently, the principle of 'growing but compensating' contravenes the Paris Agreement's core goal of reducing GHG emissions. Given its flexibility, and distance from the sources of pollution, CORSIA is a palatable response for states and airline companies, which insist in maintaining the sector's growth. The offset mechanism allows them to shift the global scale of aviation emissions to the local scale of compensation, thereby disassociating civil aviation from its contribution to climate change. The mechanism thus promotes a separation between the recognition of the seriousness of the problem of climate change and the significant contribution of aviation one the one hand, and the need to develop a mechanism capable of engaging actors and mobilising institutions to respond to this problem on the other.

\section{Notes}

1 The UNFCCC Annex I Countries (industrialised countries and countries in transition) are: Australia, Austria, Belarus, Belgium, Bulgaria, Canada, Croatia, Czech Republic, Denmark, Estonia, Finland, France, Germany, Greece, Hungary, Iceland, Ireland, Italy, Japan, Latvia, Liechtenstein, Lithuania, Luxembourg, Monaco, Netherlands, New Zealand, Norway, Poland, Portugal, Romania, Russian Federation, Slovakia, Slovenia, Spain, Sweden, Switzerland, Turkey, Ukraine, United Kingdom, United States of America. 
2 The Montreal Protocol on Substances that Deplete the Ozone Layer, signed in 1987, establishes a mandatory timetable for the phase-out of ozone-depleting substances, including CFCs, halons and HCFCs.

3 Article 3.1 (Principles) of the UNFCCC states: 'The Parties should protect the climate system for the benefit of present and future generations of humankind, on the basis of equity and in accordance with their common but differentiated responsibilities and respective capabilities. Accordingly, the developed country Parties should take the lead in combating climate change and the adverse effects thereof.'

4 Article 2.2 of the Kyoto Protocol states: 'The Parties included in Annex I shall pursue limitation or reduction of emissions of greenhouse gases not controlled by the Montreal Protocol from aviation and marine bunker fuels, working through the International Civil Aviation Organization and the International Maritime Organization, respectively'.

5 Chapter XVIII of the Chicago Convention provides a framework for sanctions (suspension of voting powers). Article 84 states: 'If any disagreement between two or more contracting States relating to the interpretation or application of this Convention and its Annexes cannot be settled by negotiation, it shall, on the application of any State concerned in the disagreement, be decided by the Council. No member of the Council shall vote in the consideration by the Council of any dispute to which it is a party. Any contracting State may, subject to Article 85, appeal from the decision of the Council to an ad hoc arbitral tribunal agreed upon with the other parties to the dispute or to the Permanent Court of International Justice. Any such appeal shall be notified to the Council within sixty days of receipt of notification of the decision of the Council'.

6 The term 'field' (Bourdieu 2007) is used to characterise spaces endowed with a certain autonomy, based on a differentiation with other spaces within which they occur, from a logic endowed with specifics, internal dispute by domain, and recognition of authority. Therefore, fields are understood as spaces in which actors share certain practices, symbols, behaviour, principles and rules, and in which specific power relations are established.

7 The EU Emission Trading System (EU ETS) was established by Directive 2003/87/CE of 13 October 2003. It is the largest cap and trade system in the world. The two main objectives of the EU ETS are to reduce GHG emissions in the EU. and encourage investment in low-carbon production. The system limits (caps) the total volume of GHG emissions from aircraft installations and operations, covering around $50 \%$ of $\mathrm{EU}$ emissions. Activities included in the system must be licensed to emit GHG, and each license gives the holder the right to emit one ton of carbon dioxide. Some of the allowances are allocated by the EU free of charge, and the rest can be purchased or sold. It is possible to negotiate emission allowances, the EU Allowances (EUAs), in the market. Part of the licenses is auctioned by EU member states, which decide the auction process.

8 Cap and trade is an economic instrument, generally structured by an emissions trading system, with the following central elements: i) the establishment of an emission limit (cap), which will explain the degree of ambition of the policy; (ii) emission allowances; and (iii) a mechanism for the allocation of emission allowances.

\section{References}

Air Transport Action Group (ATAG). 2013. Reducing Emissions from Aviation through Carbon-neutral Growth from 2020. At: https://www.iata.org/policy/environment/Documents/atag-paper-oncng2020-july2013.pdf [Accessed on 13 April 2014].

Arjomandi, Amir and Juergen Heinz Seufert. 2014. 'An Evaluation of the world's major airlines' technical and environmental performance'. Economic Modelling. 133-144. At: http://www.sciencedirect.com/science/article/pii/S0264999314001692 [Accessed on 4 March 2015].

Australian Government. 2014. Clean Energy Future: Starting Emissions Trading on 1 July 2014 - Policy Summary. At: http://www.climatechange.gov.au/sites/climatechange/files/files/reducing-carbon/ carbon-pricing-policy/cef-policy-summary-moving-ets.PDF [Accessed on 13 February 2014]. 
Böhm, Steffen and Siddartha Dabhi (eds). 2009. Upsetting the Offset: The Political Economy of Carbon Markets. London: May Fly. At: http://www.thecornerhouse.org.uk/sites/thecornerhouse.org.uk/ files/UpsettingtheOffset.pdf [Accessed on 20 February 2017].

Campos, Pamela A. 2016. 'A market-based measure for international aviation: need, design, and legal form. Carbon and Climate Law Review, 2/2016 (Vol 10): 93-96. At: http://cclr.lexxion.eu/issue/ CCLR/2016/2 [Accessed on 10 January 2017].

Carbon Market Watch. 2013. 'International aviation: addressing emissions while respecting equity issues'. Facts 36. June. At: http://carbonmarketwatch.org/wp-content/uploads/2013/05/BftW+CMWPolicy-Brief-on-international-aviation-Facts_36.pdf [accessed on 14 January 2014].

Dee, Megan. 2011. Evaluating European Union Leadership in International Multilateral Negotiations: A Framework for Analysis. European Union Studies Association (EUSA) $12^{\text {th }}$ Biennial International Conference, Regency Hyatt Hotel, Boston, Massachusetts. March.

Dooley, Kate. 2009. 'Counting the cost: forest credits and their effect on carbon markets: avoiding deforestation and degradation'. Briefing Note 6. Fern Foundation, UK, June. At: http://www.fern.org/ sites/fern.org/files/counting\%20the\%20cost_0.pdf. [Accessed on 20 February 2017]

Elsworth, Rob and Phil MacDonald. 2014. Aviation and the EU ETS: What Happened in 2012 during 'Stop the Clock'? Sandbag Climate Campaign. December. At: http://www.sandbag.org.uk/site_media/pdfs/reports/Sandbag_Aviation_and_the_EU_ETS_2012_171213_1.pdf [accessed on 12 January 2014].

European Commission. 2014. Regulation (EU) n. 421/2014 of the European Parliament and of the Council of 16 April 2014 amending Directive 2003/87/EC establishing a scheme for greenhouse gas emission allowance trading within the Community, in view of the implementation by 2020 of an international agreement applying a single global market-based measure to international aviation emissions. At: http://eur-lex.europa.eu/legal-content/EN/TXT/HTML/?uri=CELEX:32014R0421\& from $=$ PT [Accessed on 12 May 2014].

FERN Foundation. 2016. 'International Civil Society Statement'. April 2016. At: http://www.fern. org/sites/fern.org/files/briefingnote_airplane_1.pdf [Accessed on 14 September 2016].

Gilbertson, Tamra and Oscar Reyes. 2009. 'Carbon trading: how it works and why it fails. Critical Currents, 1 (31). At: http://www.carbontradewatch.org/publications/carbon-trading-how-it-worksand-why-it-fails.html [Accessed on 21 February 2016].

Gonçalves, Veronica Korber. 2016. 'A União Europeia na Governança do Clima: O Caso da Aaviação Civil Internacional'. PhD Thesis. At: http://repositorio.unb.br/bitstream/10482/21330/1/2016_ VeronicaKorberGon\%C3\%A7alves.pdf [Accessed on 20 Feb. 2017].

2011. 'O Mecanismo de Desenvolvimento Limpo e a Suinocultura no Oeste Catarinense: Análise da Implementação do Programa $3 S$ da Sadia no Município de Concórdia/SC. MA Dissertation. At: https://repositorio.ufsc.br/bitstream/handle/123456789/94348/280495. pdf? sequence $=1$ \&isAllowed $=y$ [Accessed on 20 Feb. 2017].

Greenair. 2015. 'New Paris draft agreement removes text on international aviation $\mathrm{CO}_{2}$ reduction targets and climate finance.. 8 October. At: http://www.greenaironline.com/news.php?viewStory=2139 [Accessed on 12 November 2015].

Gupta, Joyeeta. 2008. 'Global change: analyzing scale and scaling in environmental governance'. In: Oran R Young, Leslie A King and Heike Schroeder (eds), Institutions and Environmental Change: Principal Findings, Applications, and Research Frontiers. Cambridge, MA and London: MIT Press. 
Intergovernmental Panel on Climate Change (IPCC). 1999. Aviation and the Global Atmosphere: A Special Report of IPCC Working Groups I and III. Cambridge University Press. At: http://www.ipcc. ch/ipccreports/sres/aviation/ [Accessed on 20 February 2017].

2013. Climate Change 2013: The Physical Science Basis: Contribution of Working Group I to the Fifth Assessment Report of the Intergovernmental Panel on Climate Change. Cambridge University Press. At: https://www.ipcc.ch/pdf/assessment-report/ar5/wg1/WGIAR5_SPM_brochure_en.pdf [Accessed on 20 February 2017].

2014. Climate Change 2014, Impacts, Adaptation, and Vulnerability - Summary for Policymakers. At: https://www.ipcc.ch/pdf/assessment-report/ar5/wg2/ar5_wgII_spm_en.pdf [Accessed on 20 February 2017].

International Air Transport Association (IATA). 2015. Influence Map. At: http://influencemap.org/ influencer/International-Air-Transport-Association-IATA [Accessed on 5 November 2015].

2016. IATA Carbon Offset Program. At: http://www.iata.org/whatwedo/environment/Pages/carbon-offset.aspx [Accessed on 14 Sept. 2016].

International Civil Aviation Organization (ICAO). [1944] 2017. Convention on International Civil Aviation, Chicago, USA, 7 December 1944. At: http://www.icao.int/publications/Documents/7300_ orig.pdf [accessed on 20 February 2017].

. 2013a. Report of the Assessment of Market-based Measures. Doc 10018. At: http://www.icao. int/Meetings/GLADs-2015/Documents/10018_cons_en.pdf [accessed on 10 September 2016].

. 2013b. Resolution A38-18. At: http://www.icao.int/Meetings/a38/Documents/Resolutions/ a38_res_prov_en.pdf [Accessed on 19 October 2016].

.2016a. Resolution A39-3. At: http://www.icao.int/environmental-protection/Documents/Resolution_A39_3.pdf [Accessed on 19 October 2016].

2016b. On Board: A Sustainable Future. 2016 Environmental Report. Environment Branch. At: http://www.icao.int/environmental-protection/Documents/ICAO\%20Environmental\%20Report\%202016.pdf [accessed on 20 February 2017].

. 2017a. Carbon Offsetting and Reduction Scheme for International Aviation (CORSIA). At: http://www.icao.int/environmental-protection/Pages/market-based-measures.aspx [Accessed on 21 February 2017].

. 2017b. CORSIA Background Information. At: http://www.icao.int/environmental- protection/Pages/CORSIA_Background_Information.aspx [accessed on 20 February 2017].

Latam Airlines Group. 2014. Relatório de Sustentabilidade. At: http://www.tam.com.br/b2c/vgn/ img/pdfs/relatrio_sustentabilidade_2014_completo_pt.pdf [Accessed on 19 July 2015].

United Nations Framework Convention on Climate Change (UNFCCC). 1997. Kyoto Protocol of the United Nations Framework Convention on Climate Change. At: http://unfccc.int/essential_background/kyoto_protocol/items/1678.php. [Accessed on 20 February 2017].

. 1992. United Nations Framework Convention on Climate Change. At: http://unfccc.int/key_ documents/the_convention/items/2853.php [Accessed on 20 February 2017].

. 2015. Paris Agreement. At: http://unfccc.int/paris_agreement/items/9485.php [Accessed on 20 February 2017].

Vaishnav, Parth. 2016. 'Design of a global market-based measure: ICAO's market based mechanism: keep it simple. Carbon and Climate Law Review, 2 (10): 120-126. 
Zillman, John W. 2009. 'A history of climate activities'. World Meteorological Organization Bulletin, 58 (3) [online]. At: https://public.wmo.int/en/bulletin/history-climate-activities [Accessed on 20 February 2017].

\section{Acknowledgements}

The article is based on the author's PhD thesis (Gonçalves 2016), which has been financed by the National Council for Scientific and Technological Development (CNPq).

\section{About the author}

Veronica Korber Gonçalves is Professor in the Department of Economy and International Relations of the Federal University of Rio Grande do Sul (UFRGS), Brazil. She holds a $\mathrm{PhD}$ in International Relations from the University of Brasília (UnB), an MA in Law and in Political Sociology from the Federal University of Santa Catarina (UFSC), and a BA in Law from the same institution. Her fields of research and publication include Global Environmental Politics, International Environmental Law and Theories of International Relations, as well as topics related to climate governance. She is a member of the following research groups: Ecologic Justice Observatory (UFSC); International System in the Anthropocene and Climate Change (UnB).

Received on 25 October 2016, and approved for publication on 24 February 2017. 